\title{
Логика в России и православная церковь ${ }^{1}$
}

\author{
B. А. БАЖАНОВ
}

\begin{abstract}
Russia's government was suspicious toward philosophy and at the mid of XIX century ousted philosophy from University curriculum. Nevertheless ban of philosophy have no impact on logic which was taught by philosophers as well. Study of logic continued in all Russian Universities though the program was compiled by Moscow Spiritual academy and approved by Holy Synod. We discuss the feature of this program and stress crucial role of Orthodox Church in preserving logical traditions in Russia during XIX - turn of XX centuries.
\end{abstract}

Keywords: formal (traditional) logic, Orthodox church, logical education

Формальная (традиционная) логика в России во многом развивалась в контексте университетской философии, и хотя судьба университетской философии была непростой, особенно в провинциальных городах, логика страдала от метаморфоз с преподаванием философии в России в меньшей степени именно благодаря тому, что она преподавалась и в Духовных академиях (Казань, Киев, Москва, Петербург), и в Духовных семинариях (Воронеж, Вятка, Коломна, Нижний Новгород, Симбирск, Тверь и т.д.). Более того, достойный статус логики в Духовных учреждениях России и наличие подготовленных преподавателей логики из числа священнослужителей позволил обеспечить непрерывность логического образования в России XIX в. в университетах на «православной» территории, где преподавание философии в 1850 г. было запрещено. Так, Высочайшее повеление Николая I об ограничении преподавания философии в университетах и Ришельевском Лицее накладывало запрет на

\footnotetext{
${ }^{1}$ Работа поддерживалась грантами РГНФ (№10-03-00540а) и ФЦП Министерства образования и науки РФ «Научные и научно-педагогические кадры инновационной России» на 2009-2013 гг.
} 
преподавание философии, но оно не касалось логики и психологии, которые также преподавались философами и числились философскими дисциплинами. В повелении говорилось: «Государь Император Высочайше повелеть соизволил:

1) С упразднением преподавания философии светскими профессорами в университетах Санкт-Петербурга, Московском, Св. Владимира, Харьковском и Казанском, а также в главном Педагогическом институте и Ришельевском лицее, возложить чтение логики и опытной психологии на профессоров богословия или законоучителей, назначенных к этой должности по сношению Министерства Народного Просвещения с духовным ведомством Православного исповедания.

2) Профессоров богословия и философии из лиц духовного сана в означенных выше университетах и главном педагогическом институте сравнить в окладах жалованья с ординарными профессорами, присовокупив к тому и производство квартирных денег, определенных по этому званию, если они не живут в церковных домах или не имеют казенного помещения. . .

6) Программы преподавания логики и опытной психологии утвердить по соглашению духовного православного ведомства с Министерством Народного Просвещения» [5, с. 1414].

Таким образом, правительство не разделяло мнения П.Я. Чаадаева о том, что русским западный силлогизм чужд. Любопытно, что данное Высочайшее повеление не касалось неправославных конфессиональных образовательных центров в России, например, университета в Дерпте. Священнослужители читали логику и в годы, свободные от гонения на философию, причем в некоторых университетах они являлись фактически постоянными преподавателями логики. Такое положение вещей имело место, например, в Императорском Казанском университете, где в разные периоды логику читали архимандрит Гавриил, священник Грузинской церкви в Казани А.П. Владимирский, профессора Казанской Духовной академии В.А. Снегирев, В.И. Несмелов. Духовные академии постоянно и успешно готовили преподавателей логики. Так, питомцами Киевской Духовной академии являлись такие известные преподаватели логики, как Д.М. Велланский (1774-1847), С.С. Гогоцкий (1813-1889), В.Н. Карпов (1798-1867), О.М. Новицкий (1806-1884), М.М. Троицкий 
(1835-1899), П.Ф. Юркевич (1827-1874); Московской Духовной академии архимандрит Гавриил (1795-1868), М.И. Каринский (1840-1917), Н.И. Надеждин (1804-1856); Казанской Духовной академии В.А. Снегирев (1841-1889), Санкт-Петербургской Духовной академии М.И. Владиславлев (1840-1890); Костромской Духовной семинарии А.С. Лубкин (1771-1815), Нижегородской (и несколько курсов Казанской Духовной академии) - Ф.А. Зеленогорский (1839-1909) и др.

Православные журналы («Вера и разум», «Православный собеседник» и т.п.) постоянно и, видимо, весьма охотно публиковали статьи по логической проблематике (подробнее об истории логики в России см.: [4]).

Между Российскими университетами и Духовными академиями существовала тесная связь, которая выражалась не только в том, что священнослужители преподавали логику (и иные философские предметы) в светских университетах России, но и нередко переходили в них на постоянную работу. После Введения нового Устава Российских университетов 1863 г. начался усиленный отток ученых из Духовных академий в университеты. Так, в грамоте Казанского университета, врученной Казанской Духовной академии по случаю ее пятидесятилетия, говорится: «Прилив ученых сил из Казанской Духовной академии в Казанский университет особенно усилился со времени введения университетского Устава 1863 г., открывшего в университетах новые кафедры церковной истории и церковного права и возобновившего кафедру философии. Первые две из них замещались и замещены в настоящее время $(1892$ г. - B.Б.) в нашем университете исключительно питомцами Казанской Духовной академии, а кафедра философии во многом обязана содействию ее ученых сил» [6].

Бывало, что священнослужители выступали оппонентами по логическим диссертациям. Например, по диссертации крупного русского логика Л.В. Рутковского «Основные типы умозаключений», защищенной им в Казанском университете 23 апреля 1889 г., оппонентом являлся Ф.А. Курганов, профессор церковной истории Казанской Духовной академии. Другими оппонентами по защите Рутковского являлись профессора Казанского университета А.И. Смирнов и С.П. Орлов. 
После октябрьского переворота, когда стали закрываться Духовные центры образования, российские университеты принимали в число преподавателей своих коллег-священнослужителей. Так, были приняты на работу в университет В.А. Керенский (о В.А. Керенском см.: [1]), М.Н. Ершов, а чуть раньше В.И. Несмелов - профессора Духовной академии. Совет университета постановлял: «а) пригласить в качестве временного преподавателя по кафедре философии профессора В.И. Несмелова, не подвергая его обычной, установленной для соискателя этого звания промоции, ввиду наличности у него солидных научных трудов и числящегося за ним долговременного стажа преподавания в в.у.з.; б) принимая во внимание исключительные заслуги профессора В.И. Несмелова и необеспеченность преподавания философских предметов на факультете, поручить ему, В.И. Несмелову, в 1920-21 учебном году чтение курсов логики 2 часа и истории новой философии 2 часа в неделю» [7].

Вскоре, однако, В.И. Несмелову запретили чтение лекций. Коллеги по кафедре философии после запрета на чтение лекций В.И. Несмелову обосновывали незаменимость и безусловную полезность преподавания В.И. Несмелова. В ход были пущены даже административные «ухищрения». Так, в явочном порядке Ученый совет факультета общественных наук $(\Phi \mathrm{OH})$ на заседании от 20 июля 1921 г. постановил: «Ввиду того, что профессора бывшего историко-филологического факультета В.А. Керенский, В.И. Несмелов и К.В. Харлампович не утверждены профессорами ФОН, а между тем имеющиеся в плане преподавания курсы не могут быть обеспечены преподаванием без означенных лиц... - поручить всем троим на правах временных преподавателей ведение. . . общих курсов. .. »

В.И. Несмелову поручались курсы логики и истории мировоззрений на правовом факультете [8]. К.И. Сотонин обращается в Совет ФОН со следующей запиской, призывающей решить вопрос о чтении лекций В.И. Несмеловым принципиально: «В.И. Несмелов - один из наиболее оригинальных и выдающихся русских мыслителей и то, что он был профессором в духовной академии, отнюдь не уменьшает его заслуг перед наукой. Все сочинения В.И. Несмелова несут след большого критического ума и совершенно чужды ненаучной догматичности 
и правоверной безапелляционности. . . Историческая объективность профессора Несмелова не раз проявлялась в том руководстве, которое он давал своим немалочисленным ученикам. . . Такому руководителю в области историко-философских наук мог бы позавидовать не один университет; и понятно, что, пройдя школу В.И. Несмелова, его ученики чувствовали затхлость, научную фальшивость академической псевдонауки и стремление перейти в свободную высшую школу... Но с наибольшим блеском талант профессора Несмелова раскрылся в теоретических сочинениях, посвященных преимущественно вопросам теории познания. . . Главное сочинение «Наука о человеке». . . создало В.И. Несмелову всероссийскую известность как вполне самобытному мыслителю. То, что эта книга Несмелова выдерживает два издания, показывает, что мы имеем здесь дело с выдающимся явлением в области философской мысли... Если бы он писал не на русском, а на одном из западно-европейских языков, он имел бы мировое имя.

В.И. Несмелов чужд ортодоксальности религиозного мировоззрения. Он еще не сказал своего последнего слова, и можно было бы надеяться, что получивши, наконец, возможность свободного развития своих воззрений с университетской кафедры, он даст нам ряд новых блестящих трудов, но неожиданное увольнение разрушает эту надежду и лишает В.И. Несмелова возможности выявить свое творчество, принуждая его тратить свои ценные силы на бесплодную канцелярскую работу для добывания средств к существованию» (11 ноября 1921 г.) [9].

Нельзя не заметить в приведенной записке элементы нарождающегося «новояза» - ненаучная догматичность, правоверная безапелляционность и т.д. Их требовали соображения убедительности, призванные воззвать к чувствам и настроениям новых властей, «обласкать» их своей знакомостью и лояльностью, равно как и заверить их в чувствах богоборчества.

В 1921 г. «пайковая комиссия» Казанского университета ходатайствовала о назначении В.И. Несмелову и В.А. Керенскому, лишенным академического пайка, этого пайка «ввиду их незаменимости» [10]. Тем не менее, осенью 1922 г. по решению Народного Комиссариата по просвещению РСФСР В.И. Несмелов был исключен из списка преподавателей создававшегося 
вместо историко-философского факультета общественных наук. На его руках осталось четверо детей и жена... Становление советской власти ознаменовалось не только гонением на церковь, но и на формальную логику, которая рассматривалась как «метафизическая» по своей сущности науки. Она была исключена из всех учебных программ и не преподавалась вплоть до конца 1940 гг. [3].

Ныне Православная церковь располагает мощным потенциалом воздействия и на общество, и на сферу образования. Однако реформы высшего образования последнего времени ведут к значительным потерям логикой своих позиций в высшей школе. Православная церковь, похоже, утратила те традиции, которые были связаны с поддержкой логики в XIX - начале XX столетий, и (пока?) не проявляет ни малейшей озабоченности складывающимся положением вещей. . .

В 1850 г. в Московской Духовной академии составляется программа по логике, которая утверждается Святейшим Синодом и рассылается во все университеты России. Ее содержание, повидимому, в целом совпадало с содержанием университетских курсов, которые читались до запрета преподавания философии. Однако о содержании последних мы можем косвенно судить лишь по учебникам. На настоящий момент мало известны университетские программы по логике (за исключением программы чтения математической логики, составленной в 1888 г. П.С. Порецким и которая носила неофициальный характер; подробнее см.: [2]). Поэтому анализ программы, составленной в Московской Духовной академии и одобренной особым комитетом при Священном Синоде, представляет значительный интерес как образец программы, основные пункты которой, по-видимому, были общими и для светских, и для религиозных образовательных центров [11]. В данной программе, предназначенной для университетов, надо учитывать религиозное происхождение данного документа.

Эта программа содержит следующие разделы: Введение; О началах мышления; О законах мышления; О формах мышления; Об опытном познании; О познании умозрительном.

Во Введении говорится о предмете логики, определяется точ- 
ка логического воззрения на мышление, отношение логики к иным наукам, прежде всего к психологии, подчеркивается практическое применение логики к жизни. В примечании к этому разделу приводятся различные деления логики.

В разделе «О началах мышления» подчеркивается отношение логики к природе человеческого духа, который конечен, но имеет начало от существа бесконечного, и роль логики в изменениях человеческого самосознания. Однако это самосознание надо предостеречь от пагубного притязания на совершенную независимость и поставить в прямое подчинение Откровению.

В разделе «О законах мышления» дается представление о законе вообще и его приложении к мыслительной деятельности человека. Здесь обращается внимание на три основных закона мышления - законы тождества, противоположности (исключенного третьего) (обратите внимание: именно так! - В.Б.), основания - и их роль в мышлении.

В разделе «О формах мышления» излагаются вопросы, относящиеся к понятиям (и их видам), суждениям (и их видам) и умозаключениям (и их видам). В примечании к разделу рекомендуется рассмотреть вопрос о существовании врожденных понятий.

В разделе «Об опытном познании» говорится об истоках такого познания, его формах (наблюдение, опыт, свидетельство) и предположительном их характере, о вероятностных заключениях (наведение, аналогия, гипотеза). В примечании указывается на необходимость сказать об истинном Откровении Божественном и его важности для восполнения доступных для разума теоретических и практических истин в области естественного Богопознания.

В разделе «О познании умозрительном» указывается на математику и философию, которые в некотором смысле поднимают вопрос о необходимости веры для знания в его начале и о возможности колебания между догматизмом и скептицизмом.

Программа рекомендует и некоторые учебники по логике, причем только немецких авторов (Ф. Бахмана, учебник которого по логике к появлению программы уже имелся в русском переводе, Ф.А. Тренделенбурга, учебник которого был издан на русском только в 1868 г., а также Й. Зайлера). Ни один отечествен- 
ный учебник, которых к моменту появления программы было в каком-то смысле достаточно, не рекомендовался. По-видимому, составители программы считали их не вполне совершенными. В программе, которая приводится ниже, по возможности сохранены синтаксические особенности оригинала.

\section{Литература}

[1] Бажанов В.А. Владимир Керенский: жизненный путь и академическая карьеpa // Вече, 2003. Вып. 14. С. 88-99.

[2] Бажанов В.А. П.С. Порецкий. Жизнь и научная деятельность пионера исследований в области математической логики в России // Логические исследования. Вып. 11. М.: Наука, 2004. С. 23-33.

[3] Бажанов В.А. Партия и логика. К истории одного судьбоносного постановления ЦК ВКП(б) 1946 года // Логические исследования. Вып. 12. М.: Наука, 2005. C. 32-48.

[4] Бажанов B.A. История логики в России и СССР. Концептуальный контекст университетской философии. М.: Канон,+ 2007.

[5] Сборник постановлений Министерства Народного Просвещения. Т.III. СПб., 1855.

[6] Национальный архив Республики Татарстан (НА РТ). Фонд 977. Оп. Совет. Д. 8724. С. 36.

[7] НА РТ. Фонд 1337. Оп. 1. С. 103.

[8] НА РТ. Фонд 1339. Оп. 27. Д. 11. С. 44.

[9] НА РТ. Фонд 1337. Оп. 27. Д. 13. С. 82-84.

[10] НА РТ. Фонд 1337. Оп. 27. Д. 11. С. 58.

[11] НА РТ. Фонд 977. Оп. Совет ист.-фак. Д. 614.

\section{Программа логики}

\section{Введение}

Предмет логики есть мышление. Мышление есть деятельность ограниченного человеческого духа, стремящегося обнять в единстве сознания разнообразные предметы мира видимого, собственную природу и отношения их к Верховному началу всего.

Точка логического воззрения на мышление. Мышление должно быть преимущественно или предметом опыта, - рассматриваемое в своих действительных обнаружениях, или предметом умозрения, - рассматриваемое в своей сущности, в том, что есть и должно быть в нем всеобщего и необходимого, по требованию его начала и цели: первое исполняет Опытная Психология, последнее логика.

Отсюда определяется отношение логики к наукам вообще и к Психологии в особенности. Прочие науки суть плоды мышления, 
обращенного на те или другие предметы действительности; в логике же предметом мышления становится самомышление. Это обращение мышления на само себя возможно для него не иначе как посредством отвлечения от предметов сторонних к наблюдению собственных произведений и действий, таким образом в порядке происхождения логике предшествуют другие науки, и ближайшим образом - психология, в которой подвергается наблюдению естественный ход мышления в человеке. От сего наблюдения и при помощи его логика переходит уже к законам и формам, необходимым в мышлении по самой природе мыслящего духа, и начертывает правила, составляющие условия истинности человеческого мышления. В последнем отношении логика в свою очередь имеет обратное действие на все отрасли знания, как методологическое руководство.

Практическое применение ее к жизни. Так как логика рассматривает мышление в отношении а) к его началу, б) к общей цели, то она естественно делится на две части: теоретическую и практическую. В первой части раскрываются общие законы и формы мышления, из самой природы мыслящего духа происходящие, во всех людях необходимо имеющие свое действие и никакими условиями внешними со стороны предметов мышления не стесняемые. Во второй рассматривается мышление как свободная деятельность человека, долженствующая по возможности достигать своей цели, т.е. согласия с действительным бытием познаваемых предметов, или истины: здесь представляются внешнею, с одной стороны, границы, в которых является сия деятельность, вследствие зависимости от произвола человека и от условий бытия, как его собственного, так и самих предметов познания; с другой - средства, при которых мышление может быть согласно со своим предметом и достигать возможного совершенства.

Примечание. Другие деления логики, - на антропологическую и философскую, предлежательную и подлежательную, учение элементарное и систематику и т.п., или имеют в основании своем неправильный взгляд на мышление, как предмет логики (таковы первое и особенно второе), или не довольно точные (таково третье). Разделение логики на чистую и прикладную близко к представленному нами; только названия частей неудачны. 
Что же касается пособий при изложении логики, то по неудовлетворительности и большею частью ложному направлению известных иностранных (собственно Германских) сочинений по сему предмету, можно пользоваться весьма немногими из них и то по частям, в чем какое оказывается более основательным. Теоретическую часть логики должны представить естественные законы и формы мышления в отношении к их коронному началу. Отсюда три главные отделения сей части:

1. о началах мышления

2. о законах и

3. о формах мышления.

\section{О началах мышления}

Понятие о начале вообще; различие между началом и первоначальным обнаружением, или исходной точкой. Мышление, как деятельность духовная, должно иметь начало внутреннее в самой природе человеческого духа, оно есть видоизменение его самосознания; посему за коренное начало его должно быть признано то, что есть в самосознающем духе человеческом глубочайшего, деятельнейшего, всеобщего и несомненно истинного. Глубже всего человеческий дух сознает, что он небезначален, но имеет начало от Существа Бесконечного (действительное бытие идей и Бог в человеческом духе). Идея о Боге и есть именно: а) нечто высшее в нашем духе, - не собственно силою его мышления она производится, но врожденна ему свыше, и по необъятности своего содержания безмерно превосходит все другие представления и мысли наши; б) нечто деятельнейшее в духе, чему единственно обязаны мы непреодолимым стремлением к знанию или истине, которое удовлетворяется только в познании последней, Бесконечной причины всего; в) нечто общее всем людям, хотя различно ими понимаемые; наконец е) есть нечто такое, что не только истинно само в себе, но и составляет единственное условие, по которому возможно для человека истинное познание предметов, единственное ручательство в согласии законов и форм человеческого мышления с действительным бытием вещей - что могло бы уверить нас в сем согласии, если 
бы не нашли опоры в Единого истинного Виновника и бытия и мышления?

Таким образом, как удовлетворяющая всем показанным условиям врожденная идея о Боге должна быть признана коренным началом мышления.

Примечание. Можно ли признать таким началом самое сознание? Скудность содержания в чистом самосознании, мышлении есть действующее самосознание, следовательно, если началом мышления признают самосознание, то это значило бы вовсе остановить его без начала. Между тем признание указанного нами начала ограждает знание человеческое от ложного и пагубного притязания на совершенную независимость, и поставляет в прямое подчинение Откровению, как единственно верному источнику, из которого могут быть объяснены и восполнены не довольно внятные внушения врожденной идеи о Боге в падшем человеке. Сохранение разумности в науке при такой зависимости.

\section{I}

\section{О законах мышления}

Понятие о законе вообще и в приложении к мыслительной деятельности человека. Различие между законами, самим человеком составляемым для мышления, и законами естественными по самой природе мыслящего духа, необходимо определяющими каждое действие мышления. Понятие о сих последних.

Три основные законы мышления. В каждом действии мышления, поскольку оно есть раскрытие самосознания, необходимо предполагаемое а) мыслящий субъект - нечто такое, что во всех своих действиях сознает себя одним и тем же; это существенное тождество субъекта переходить и на его отдельные представления; каждое из них может быть сознаваемо не иначе, как равным самому себе, ничего, заключающего в себе противоречие, нельзя представить; закон тождества (закон противоречия) отличаемый некоторыми от сего закона, очевидно есть не более как его отрицательная сторона. б) предполагается нечто, от чего отличает себя субъект, - разнообразные предметы мышления: из сей противоположности субъекта представляемым предметам и 
самым представлением своим выходит новый закон для сих последних, по которому каждые из них есть для сознания уже не то, что все другие, - закон противоположности (исключенного третьего). в) предполагаемое мысленное соединение субъекта с предметом в сознании (преставление), что невозможно без основания, почему из множества возможных представлений предмета составляется именно то, а не другое, закон основания. Зависимость сих законов от идеи о Бесконечном существе, которое всегда и во всем одинаково с собою, и есть безусловное начало бытия вещей и мышления человеческого.

Раскрытие закона тождества: формула его положительная и отрицательная. Значения его в мышлении, как первого условия мышления; дальнейшее приложение к знанию - твердость познаний. Закон постоянства в бытии, соответствующий закону тождества в мышлении.

Раскрытие закона противоположности; противоположность действительная (предметная) и логическая (отвлеченная): формулы закона: значение его в мышлении, преимущественно как двигателя при переходе от одной мысли к другой; дальнейшее приложение к знанию, - разнообразие и определенность познаний; что соответствует сему закону в бытии (Principum indiscernibilium).

Раскрытие закона основания, что называется собственно логическим основанием, различие его от других оснований, наприм. психологического. Формулы сего закона. Значение его в мышлении, - завершение мыслительной деятельности под влиянием сего закона; дальнейшее приложение к знанию - связность и основательность познаний. Предметное значение сего закона - закон причинности в бытии; различие между основанием и причиной.

\section{О формах мышления}

Что такое форма деятельности вообще и мышления в частности? Общая естественная форма мышления - представление. Соответственно трем основным законам мышления, мы имеем и три главные формы представления. По силе внутреннего тождества с собою, мыслящий субъект стремится приводить к единству сознания разные образы предметов, и открывая в них сход- 
ные признаки, составляет понятие. Но разности представляемых предметов в понятии не исчезают, только закрываются для сознания; и выступая снова при встрече с другими представлениями, становятся в известное отношение (логическое) к ним: представление сего отношения есть суждение. Поелику же установляя определенное отношение между мыслимыми предметами, сознание наше требует основания для сего: то представление сего основания составляет третью и последнюю форму мышления, умозаключение. Взаимная зависимость всех трех форм.

Понятие как форма мышления, по которой многие предметы сходные между собой в известных признаках (качествах или действиях) соединяются в одно представление. Две стихии, составляющие понятие: объем, т.е., предмет заключающийся в понятии, и содержание, т.е. совокупность их сходных признаков. Значение понятия в мышлении, как первой формы, в которой единство сознания возвышается над разнообразием действительного бытия и чувственных воззрений. Касательно же предметного значения наших понятий должно заметить, что - как представление, составляемое чрез отвлечение от действительных предметов, понятие может и должно соответствовать их сущности, но это соответствие отнюдь не простирается до тождества или даже равенства с ними: в ограниченном человеческом духе понятие никогда не может вступить на степень такого созерцания, которое бы зараз обнимало до последней подробности и все предметы, и их признаки; разнообразие предметов необходимо устраняется из внимания; по мере их обобщения. Отсюда обратное отношение, всегда имеющие место между объемом и содержанием понятия.

Разности понятий по объему и содержанию. По объему понятия могут быть единичные, частные и общие; сравниваемых же между собою по объему, могут быть или подчиненные (понятия рода и вида), или соподчинения. В отношении к содержанию различаются понятия по степени ясности, с какою предносятся сознанию признаки предметов, или ими обнимаемых, понятия, - темные, ясные, подробные и точные; сравниваемые между собою по содержанию понятия могут быть или сходные, или несходные, и последнем случае или согласимые, или про- 
тивоположные. Бесплодность и неосновательность дальнейшего дробления понятий.

Примечание. Есть ли понятия врожденные? Значение и образование категорий, как высших отвлеченных понятий. Исчисление их: 1) понятия бытия - действительного, возможного и необходимого; 2) понятия оснований бытия - субстанций и принадлежности, причины действия, самодеятельности и приемлемости; 3) понятия качеств бытия, существенных и случайных, совершенства и недостатка, тождества, сходства и различия; 4) понятия количества - единства, множества и всеобщности, целого и частей, простого и сложного. Недостаток систематического выведения и точного распределения категорий. Как на дельное историческое исследование категорий можно указать на Geschichte der Kategorienlehre v. Ad. Trendelenburg. Berlin. $1846^{2}$. Вообще о понятиях более удовлетворительное исследование находим в Логике Бахмана ${ }^{3}$ Ч.1 отд. IV.

Суждение, как форма мышления, в которой определяется отношение одного понятия к другому. Подлежащее и сказуемое суждение, логическая связь между ними. Отношение суждения к понятию: понятие - единство, суждение - разрешение сего единства. Значение суждения в мышлении, как необходимого перехода от одного понятия к другому; связность и определенность мышления, достигаемая посредством суждений. Поелику в суждении определяется или содержание понятия, или объем его, то суждения бывают двух родов.

В суждениях первого рода признаки предмета могут быть мыслимы или положительно, как данные в предмете, вне всякой зависимости от других предметов или от других признаков сего же предмета, - суждения категорические (субстанция и принадлежность); или предположительно, - как еще только возможные в данном предмете, в зависимости от известных предметов или от известных состояний сего же предмета, - суждения условные (основание и следствие). Совершеннейшая форма суждений сего рода есть определение.

\footnotetext{
${ }^{2}$ Тренделенбург Ф.А. (1802-1872) - немецкий логик и философ. На русском языке были изданы его «Логические исследования», ч. 1-2. М., 1868.

${ }^{3}$ Бахман Ф. (1785-1855) - немецкий логик. Его «Система логики» была переведена на русский язык преподавателем Санкт-Петербургской Духовной академии Вершинским и издана в Петербурге в 1831 г.
} 
Понятие об определении. Предмет определения - понятие ограниченное по объему и содержанию; определяющее - родовой признак и видовое отличие. Два вида определений: определение вещи по ее сущности и по происхождению (генетические). Важность определения, как средоточия познаний о предмете. Достоинства определения: а) ясность, - неясные определения отрицательные, кругообразные, выспренные; б) острое соответствие предмету - определение теснейшее и обширнейшее.

В суждениях второго рода определяется объем подлежащего или в отношении к другим соподчиненным понятиям, в совокупности с которыми оно составляет область понятия высшего суждения разделительные (взаимная противоположность членов разделительного суждения); или в отношении к низшим понятиям, его составляющим, - суждения раздробительные. Точная форма последних есть разделение. Понятие о разделении. Предмет, член и основание деления. Важность разделений для полноты и подробности знания. Достоинства разделения в выборе основания: а) единство, деления запутанные, б) твердость; в) целесообразность; касательно членов: а) взаимное различие их (смешение разделения с подразделением) и б) равенство суммы их делимому понятию, - разделение теснейшее и обширнейшее.

Кроме сих частных видов суждения известны еще общие видоизменения, которым подвергается в нем мышление, как деятельность ограниченная и по внутренней силе и со стороны и самих предметов.

Так, вследствие ограниченности каждого понятия в суждении о нем показывается или то, что принадлежит понятию, или то, что не принадлежит ему, - суждения утвердительные и отрицательные. Другое следствие ограниченности мышления есть постепенный переход от низшей степени суждения к высшей: так переходит наше мышление от суждений единичных и положительных (indicia assertoria) к частным и предположительным (indicia problemmatica) и достигает наконец суждений общих и решительных (indicia apodictica). Приложение сих видоизменений к исчисленным видам суждений.

Умозаключение (доказательство), как форма мышления, в которой одно суждение выводится из другого, как следствие из основания. Отношение умозаключения к суждению и понятию: 
восстановления единства понятий, разрешенного в суждении. Значение его в мышлении как завершительного действия; глубина и основательность мышления. Умозаключение, как средство к познанию и выражению законов действительного бытия. Два рода умозаключений: умозаключения непосредственные и посредственные.

Во-первых, одно суждение составляется из другого чрез повторение и изменение понятий, в нем заключающихся, без посредства нового понятия или суждения. В этом случае или подлежащие данного суждения изменяется в объеме, - умозаключение подчинения; или делается перестановка подлежащего на место сказуемого и наоборот (причем также необходимо обращать внимание на объем каждого из них) - умозаключение превращения (syllogismus conversionis); или сказуемое изменяется из утвердительного в отрицательное и наоборот, - умозаключение противоположения (sillogismus oppositionis), сложная форма его - дилемма: строение ее, сила доказательная и условия правильности; или наконец такое изменение соединяется с перестановкой подлежащего и сказуемого, - умозаключение противопоставления (sillogismus contrapositionis).

В умозаключениях второго рода, между подлежащим и сказуемым данного суждения, посредствует новое понятие, третье, служащее опорой их соединения (две посылки и заключение). В этом случае или содержание среднего понятия (сказуемое большей посылки) наводится на предметы, составляющие объем его (подлежащее заключение), или наоборот, от частных предметов, составляющих объем сего понятия, делается заключение к содержанию целого понятия. Первое умозаключение прямое, второе обратное. Строение того и другого, доказательная сила и условия правильности. Строение непрерывного ряда заключений (сорит). Паралогизм и софизм; происхождение софизмов и способ их разрешения; известнейшие софизмы в древности; софизмы в практической жизни.

Примечание. О пустых тонкостях в силлогистических фигуpax. По простоте и отчетливости изложения заслуживает внимания трактат о суждении и умозаключении. . .

Практическая часть и логика должны рассмотреть мышление человеческое как деятельность, долженствующую достигать 
своей цели. Цель эта заключается в возможно точном соответствии мышления своему предмету по объему и содержанию, или в познании истины. По необъятности предмета и по ограниченности мыслящего субъекта, такое соответствие очевидно может быть достигаемо не иначе, как постепенно. Первоначально мышление состоит преимущественно под влиянием чувства внешнего и внутреннего, извещающего нас о явлениях природы и духа человеческого; отсюда уже возвышается к идеям ум, открывающим последнюю причину и конечную цель всего сущего: таким образом различаются две главные степени, или два рода познания; - познание опытное и умозрительное. Отсюда два отделения в практической части логики.

\section{Об опытном познании}

Мышление в пределах опыта также имеет различные степени; по самому предмету и внутренней силе. Ближайшим предметом его служат отдельные явления природы и жизни человеческой, в отношении к которым она обнаруживается наблюдением, наглядное познание. Так как познание, ограничивающееся наблюдениями одного лица, составляет самую незначительную величину в сравнении с неисчерпаемым разнообразием предметов, то настоит нужда в обмене познаний между людьми, в котором бы эта скудость личной опытности по возможности восполняет общею опытностью человечества, познание историческое. То и другое познание различаются только размерами и способом преображения; предмет же их един - явления природы и человеческого духа. Когда же по вере в разумный порядок сущего и по самым указаниям опыта разум наш старается открыть в сих явлениях общие силы и законы: то в этом случае его деятельность обнаруживается рядом предположительных заключений, завершающих опытное познание.

Наглядное познание. Источник его: воззрения чувства внешнего и внутреннего. Характер его: очевидность, уверенность в истинность чувственного воззрения, нераздельная с самосознанием и несомненная при мысли о Едином истинном Виновнике природы и духа человеческого. Действительное бытие внешнего мира. Идеализм: логическая несообразность идеализма; вред- 
ные следствия его для науки; вред и странность идеализма в практической жизни.

Общая форма наглядности познания - наблюдение. Различие наблюдения от воззрения - участие свободы в наблюдении; целесообразность его. Возможность неправильных наблюдений. Условия их правильности: а) со стороны самого предмета наблюдение предмета - в его особенности и в связи с другими; б) со стороны лица наблюдающего - устранение случайных и постоянных недостатков в чувственных органах, чистота посредства между предметом и органом, соразмерная степень силы и продолжительности впечатления, поверка одного органа другим, сосредоточение внимания на предмете, ясность духа и свобода от предзанятых мнений, повторение наблюдения и т.п. Опыты (experimenta) как пособия наблюдений. Понятия об опытах, значение их - в упрощении, уяснении и расширении наблюдаемых действий природы. Условия успешности опытов: предварительные сведения, точнее определение задачи, снаряд и умение им пользоваться; повторение опытов и переход от одного к другому. Приложение сих правил к наблюдению внутренней жизни человека, трудность самонаблюдения и его особенности.

Историческое познание. Понятие о свидетельстве и вере исторической. Основание Исторической веры в природе человека, и ее различие от веры религиозной. Характер исторического познания - достоверность. Условия достоверности свидетельства: а) со стороны предмета - возможность его логическая и физическая (замеч. о чудесах); б) со стороны лица, свидетельствующего, - хорошо ли известно ему сообщаемое дело им, и точно ли он передает его? Внутренние и внешние средства к открытию того и другого. Усвоение свидетельства; подлинность свидетельства (задача и главные приемы герменевтики). Свидетельства непосредственные и посредственные; значение последних; ряд свидетельств, сличение свидетельств. Трудность пособия исторической критики; крайность ее.

Примечание. Нужные подробности касательно исторического и наглядного познания можно найти в Логике Бахмана Ч.Г. от. II и особенно в Vernunftlehre v. Sailer I. B. I. Th. I. Absehn ${ }^{4}$.

О высочайшем свидетельстве истины в Божественном откро-

\footnotetext{
${ }^{4}$ Зайлер Й. М. (1751-1832) - немецкий теолог и философ.
} 
вении. Понятие об истинном откровении Божественном. Необходимость Божественного откровения, как для поверки и восполнения, доступных для разума, теоретических и практических истин в области естественного Богопознания, так и для возведения ума к непостижимым тайнам Божественным, без принятия которых полное удовлетворение существенным потребностям духа человеческого невозможно. Признаки истинного откровения - а) в истине и возвышенности истин, в нем содержащихся, б) в достоинстве лиц, служивших органами чувств при его сообщении и в) в чудесных событиях, коими ознаменовано его возвещение и распространение. Нужное предостережение для разума: не сделать заключение от непостижимости к невозможности, и признавать необходимою при суждении о вещах Божественных внутреннюю жизнь в общении с духом Божьим (кор. 2, 10, 16).

Примечание. Хорошие о сем предмете замечания можно найти у Зайлера в I т. его Vernunftlehre ст. 2. о способности веры.

Вероятные заключения - от явлений к сущности. Нужда их по ограниченности человеческого опыта; основание - вера в единство законов бытия, как необходимое условие мышления (нелепость того предположения: будто законы и порядок, открывается в природе, суть дело только нашего мышления, а не существуют на самом деле). Явление относится по сущности двояко: как частное к общему и как действие к причине: отсюда два вида вероятных заключений а) наведение и аналогия, б) гипотеза.

Понятие о наведении и аналогии. Различие между ними по предмету (количество и качество); в порядке образования наведение предшествует аналогии; результат наведения - расширение познаний, результат аналогии - подробность их. Общий характер заключений чрез наведение и аналогию - вероятность: причина, законность и пределы сомнения при сих заключениях. Понятие о вероятности и ее степени: утвердительная и отрицательная сторона вероятного; исключения или инстанции. Различные виды вероятности: вероятность математическая - число сходных случаев, и динамическая - различный вес отдельных случаев. Правило касательно наведения и аналогии: точное исследование данных, определение отрицательных случаев, 
постепенность восхождения от низших заключений к высшим. Гипотеза, как заключение от данного явления к причине его еще неизвестной. Характер гипотетического заключения - вероятность, отгадывание действительной причины между многими возможными. Отношение гипотезы к наведению и аналогии; сходство и различие; влияние гипотезы на сии заключения, как мотива и дополнения их. Значение гипотезы в знании человеческом, и преимущественно в области естествознания. Вред от приступления к гипотезам; небрежность в наблюдениях, упорство против вразумлений опыта, шаткость знания; вред в практическом отношении и т.п. и правила для составления гипотез: гипотеза неуместна при возможности объяснения точного и при значительной невозможности объяснения (действия сверхъестественные); гипотеза должна быть согласна сама с собою и ее другими дознанными истинами; должна просто и непринужденно объяснять дело, - вспомогательные гипотезы; не должна принимать решительного тона.

Примечание. Всеми правилами касательно наведения и аналогии логика обязана Бэкону; в его Novum Organon можно найти самое точное, полное и богатое применениями изложение индуктивной методы.

Методы опытного познания вообще: поступательный (аналитический) ход мышления в опыте - от частного и случайного к общему и необходимому; зависимость его от опыта; необходимость в науке и богатые результаты. Отличительные черты опытного познания: ясность предмета и твердость суждения, основывающегося на самой действительности. Пределы опытного познания: неполнота сведений всегда ощутительная, несмотря на многочисленные открытия, и недостаток несомненности в выводах. Крайность чисто эмпирического направления.

За открытием общих сил и законов бытия опытными науками остается еще одно важнейшее дело - открыть разумные основания, на которых утверждаются сии силы и законы. Решение сей задачи выступает из пределов опыта, и составляет предмет умозрения. 


\section{II}

О познании умозрительном

Источник умозрительного познания - идеи ума. Понятие об идее; различие идей от понятий по необъятности содержания,.. . и деятельной силе. Происхождение идей из одной существенной идеи о Бесконечном существе. Отношение идей к бытию вещей и субъекту мыслящему. Раскрытие идей в сознании при пособии опыта. Самодеятельность мышления под влиянием идей, обнаруживающихся идеальным построением (понятие об идеале; отношение идеала к действительности; идеалы предметов физических и духовных), идеальные построения может производить мышление: или в области феноменального бытия (в пространстве и времени), определяя его общие и необходимые формы, математика; или же возвышаясь над сею областью и возводя все сущее к Верховному началу и последней цели бытия, - философия.

Математика имеет своим предметом вообще величину, определение и уверенность в возможности истинного знания невозможны без положительного откровения истины. Необходимость Веры для знания в начале, продолжении и конце его; истинное отношение знания к Вере. Вне сего отношения неизбежны две крайности в стремлении знания к его идеалу: слепое доверие к собственной теории - догматизм и отрицание возможности истинного знания - скептицизм.

Примечание. Подробное и полезное исследование о заблуждениях и предрассудках представляет Зайлер в "Vernunftlehre" II B. Von den Hindernissen im Erkennen der Wahrheit überhaupt.

На списке написано: Верно: Исправляющий должность начальника отделения Павлиновский; читал начальник первого отдела второго отделения Департамента Министерства Народного Просвещения Титулярный Советник Валериан Толвинский. 